\title{
INTERSTITIAL EMPHYSEMA IN THE NEWBORN
}

\author{
BY \\ R. PROSSER \\ From the Department of Child Health, Llandough Hospital
}

(RECEIVED FOR PUBLICATION OCTOBER 9, 1963)

The interpretation of chest radiographs in the newborn and their correlation with the clinical picture in conditions producing cyanosis or respiratory distress is undoubtedly difficult. During the past ten years there has been a remarkable increase in the investigation of these conditions, and especially of hyaline membrane disease. A classical radiograph of the latter condition, well described by Donald (1954), is now recognized. Recently our attention has been drawn to another less common, but at times equally lethal, cause of respiratory difficulty, namely interstitial emphysema. We believe this condition is probably more common than is realized. It may be associated with a wide range of symptoms and signs. Its effects may be so mild as to go unrecognized, or alternatively may produce mild to severe cyanosis with or without other signs of respiratory distress, and death may result.

Since Donald's paper in 1954 there has been considerable clarification of the interpretation and correlation of chest radiographs with the clinical signs, leading to improvement in diagnosis. The need for a specific diagnosis during life is important. The purpose of this article is to describe four cases of interstitial emphysema and the radiological features that appear to be characteristic of the condition.

\section{Case Reports}

Case 1. This infant, a girl, the product of an uneventful pregnancy, was delivered at 42 weeks. Delivery, except for a slightly hurried second stage, was normal. Birth weight was $3,780 \mathrm{~g}$. (8 lb. $7 \mathrm{oz}$.), the Apgar score was 8 , and apart from aspiration of the upper air passages no special resuscitation was required. The infant cried lustily, was normally active, but was noted to have peripheral and central cyanosis and to be frothing slightly. A tube was successfully passed into the stomach. At the age of 35 minutes the infant, who was being nursed in an incubator, was still severely cyanosed. The temperature was $34^{\circ} \mathrm{C} .\left(93 \cdot 4^{\circ} \mathrm{F}\right.$.). She cried lustily and was normally active when disturbed. Respiratory rate was 48 a minute. There was a very slight expiratory moaning when quiet and slight insuction of the costal margins. Air entry was poor, with some fine crepitations heard in the right side of the chest. Pulse rate was $160 \mathrm{a}$ minute, apex beat was not palpable, heart sounds were soft, no murmurs were heard and the femorals were palpable. Blood pressure was $55 \mathrm{~mm}$. Hg systolic. A chest radiograph showed diffuse coarse granular shadowing of both lung fields and a normal heart.

At $4 \frac{1}{2}$ hours the infant's condition was judged to be slightly improved. There was no moaning or insuction, and the cyanosis was aggravated by crying. The respiratory rate was 54 a minute and the pulse rate $130 \mathrm{a}$ minute. The infant's condition continued relatively unchanged with no undue cause for anxiety until at 12 hours when the temperature was $33 \cdot 5^{\circ} \mathrm{C}$. $\left(92 \cdot 2^{\circ} \mathrm{F}\right.$.), respiratory rate 36 a minute, pulse rate 110 a minute. The colour then suddenly deteriorated, and the baby became pale and cyanosed with grunting and insuction. Her condition steadily deteriorated and she died aged 14 hours and 15 minutes. Other than oxygen no special therapy had been given. Autopsy showed bilateral tension pneumothorax and diffuse interstitial emphysema (Figs. 1 and 2).

Case 2. This infant, a boy, the second child of a 19year-old woman, was born at 32 weeks. The pregnancy was normal and there was no obvious cause for the prematurity. Birth weight was $1,498 \mathrm{~g}$. (3 lb. $5 \frac{1}{2} \mathrm{oz}$.), delivery was normal, the Apgar score 9. Apart from aspiration of the upper air passages no resuscitation was given. Half an hour later the infant developed grunting respirations, the typical picture of the respiratory distress syndrome. Silverman 'retraction score' was 6. Capillary blood $p \mathrm{H} 7 \cdot 25, \mathrm{PcO}_{2} 84 \mathrm{~mm}$. $\mathrm{Hg}$, base excess $+2 \cdot 7$ $\mathrm{mEq} / \mathrm{l}$. Chest radiograph showed a fine reticular granular patterning, with an air bronchogram, i.e. the typical picture of the respiratory distress syndrome. At 2 hours of age, the Silverman score was 8 . An umbilical vein infusion of sodium bicarbonate and $10 \%$ dextrose was commenced. At 6 hours the infant was noted to have improved, the Silverman score being 6 . Capillary blood $p \mathrm{H} 7.42, \mathrm{PcO}_{2} 53 \mathrm{~mm} . \mathrm{Hg}$, base excess $+8.7 \mathrm{mEq} / \mathrm{l}$. The sodium bicarbonate was discontinued but the $10 \%$ dextrose was maintained and the ambient oxygen kept at $25 \%$.

At 17 hours of age he showed a striking clinical improvement, Silverman score $2, p \mathrm{H} \mathrm{7} \cdot 35, \mathrm{PcO}_{2} 37 \cdot 5 \mathrm{~mm} . \mathrm{Hg}$, and intravenous therapy was discontinued. The ambient 


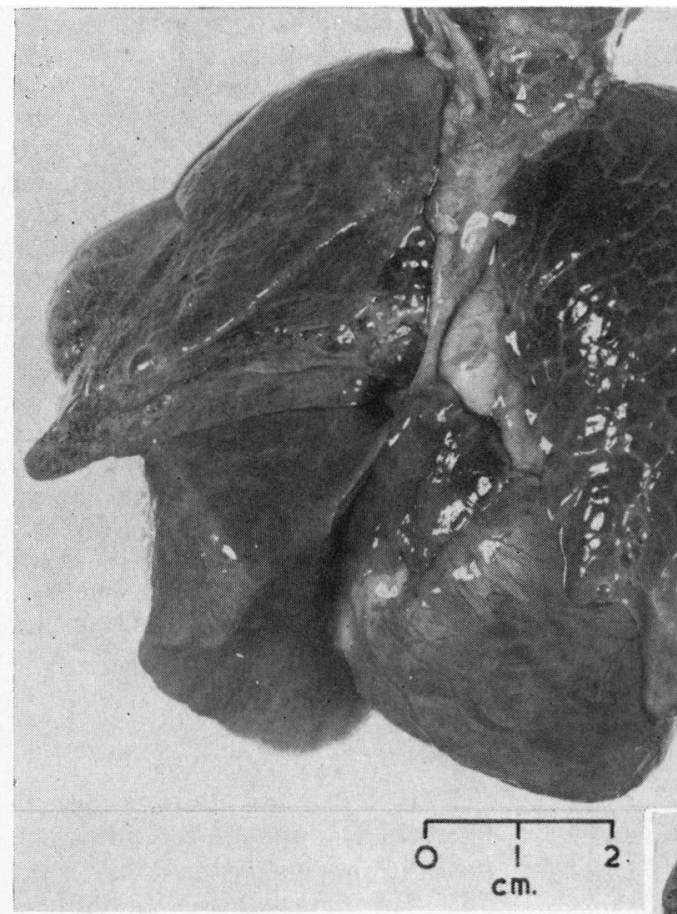

FIG. 1.-Case 1, pleural surface of lung showing interstitial emphysema

oxygen was maintained at $30 \%$. Two and a half hours later, however, the infant's condition suddenly deteriorated. He became cyanosed with considerable sternal insuction, Silverman score 7. Blood $p \mathrm{H} \mathrm{7} \cdot 23, \mathrm{PcO}_{2} 80 \mathrm{~mm} . \mathrm{Hg}$, base deficit $2 \mathrm{mEq} / \mathrm{l}$. Air entry was poor. Intravenous sodium bicarbonate infusion was recommenced and the ambient oxygen maintained at $+60 \%$. He remained cyanosed and his condition deteriorated steadily with intermittent apnoeic spells. Chest radiograph showed a diffuse coarse granular shadowing of both lungs with small scattered translucent areas and no air bronchogram. At 29 hours the capillary $p \mathrm{H}$ was $6 \cdot 6$, and the $\mathrm{PcO}_{2}$ could not be recorded. He died shortly afterwards. Autopsy showed bilateral tension pneumothorax and diffuse interstitial emphysema. No active resuscitation was given to this infant at any stage.

Case 3. This infant, a boy, birth weight $2,128 \mathrm{~g}$. (4 lb. $12 \mathrm{oz}$.), length $52.5 \mathrm{~cm}$. (21 in.) was born at home at 42 weeks by dates. A normal uneventful vertex delivery, he breathed and cried immediately, receiving no active resuscitation. He was admitted to the Premature Baby Unit at 3 hours of age because of his small size, and he was found to have the typical features of a dysmature infant. Apart from a low body temperature $34^{\circ} \mathrm{C}$. $\left(93.4^{\circ}\right.$ F.) and a slight peripheral cyanosis, the infant appeared well, being normally active and taking feeds. Ten hours after admission, however, he was noted to have mild peripheral and central cyanosis with fine crepitations over both lungs. There was no obvious respiratory distress; the respiratory rate was 40 a minute, and the

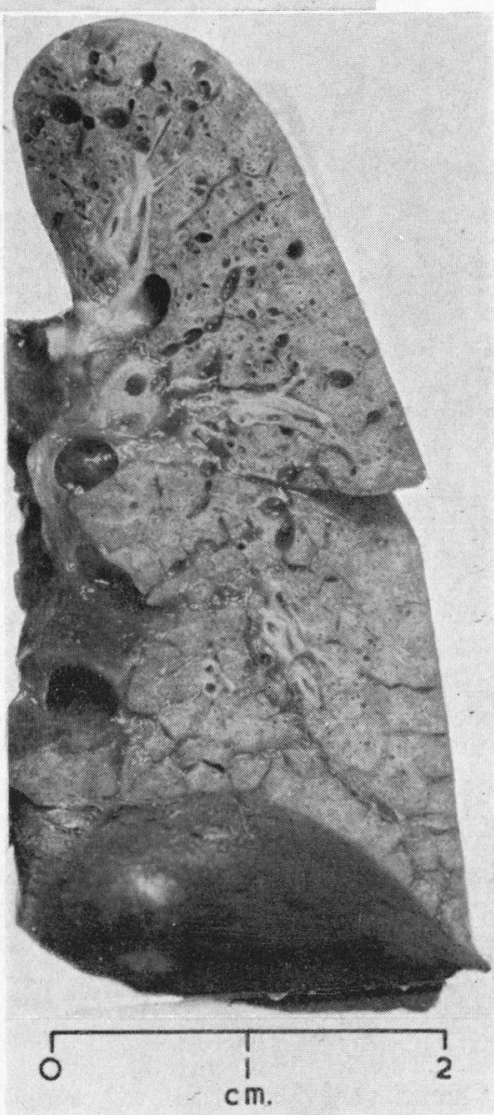

FIg. 2.-Case 1, cut surface of lung showing interstitial emphysema, 
infant was lively. A chest radiograph showed a small left-sided pneumothorax with several small radiotranslucent areas scattered in the substance of the left lung. There was mediastinal shift to the right, disproportionate to the size of the pneumothorax. An underwater drain was prepared in case of need, but apart from oxygen at $32 \%$ and intramuscular streptomycin and erythromycin, no other treatment was given.

The following day the infant's condition remained unchanged with slight cyanosis, a respiratory rate of 40 a minute, and he was feeding well. A repeat chest radiograph now showed bilateral pneumothorax with diffuse coarse reticular granular patterning, most marked in the left lung. On the third day he was clinically normal with minimal radiological changes. Recovery thereafter was uneventful.

Case 4. This male infant weighed 3,192 g. (7 lb. 2 oz.) and was born after a normal vertex delivery, but there was thick meconium-stained liquor, and the body was covered with meconium. The baby gasped immediately, and, apart from aspiration of thick meconium from the upper air passages and oxygen by face mask, no resuscitation was given. Respirations were rapid with insuction

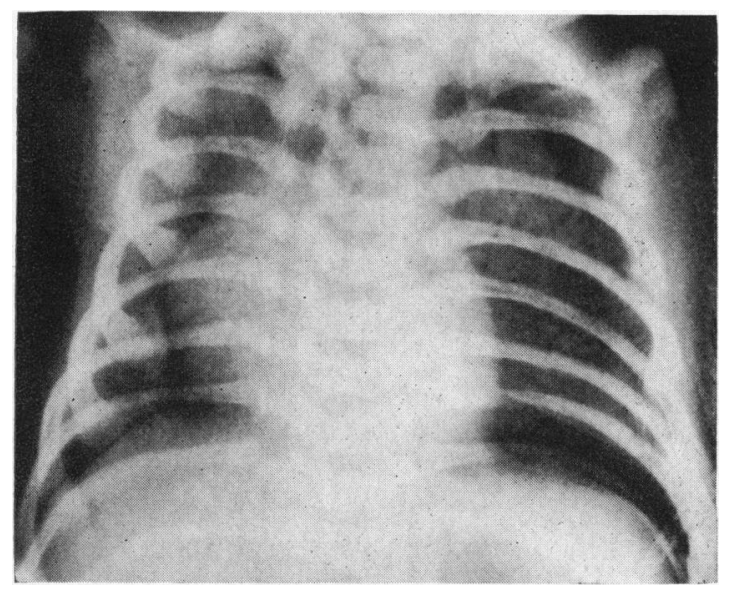

Fig. 3.-Case 4, radiograph showing left pneumothorax and scattered translucencies in the left lung.

and alae nasi working from the outset. At 1 hour the infant was in extremis with central and peripheral cyanosis, grunting respirations, insuction of intercostal spaces and bowing of the sternum. Air entry was very poor with diffuse crepitations on the left side and heart sounds heard maximally on the right. Capillary $p \mathrm{H}$ 6.95, $\mathrm{Pco}_{2} 108 \mathrm{~mm} . \mathrm{Hg}$, base deficit $14 \mathrm{mEq} / \mathrm{l}$. Chest radiograph showed a prominent left pneumothorax with displacement of the mediastinum to the right, a very clear outline to the heart and diffuse translucent areas varying in diameter from 0.5 to $2 \mathrm{~mm}$. scattered throughout the substances of the left lung (Fig. 3). The infant was intubated immediately and trochar and cannula inserted into the left chest, with a polyvinyl catheter attached to an underwater drain introduced through the cannula. A large amount of air escaped from the pleural cavity confirming the diagnosis of a tension pneumothorax. Following this the baby's condition improved remarkably with return of air entry to the left, but with numerous crepitations, reduction of insuction, and restoration of pink colour. Capillary $\mathrm{pH}$ was $7 \cdot 19, \mathrm{Pco}_{2} 72 \mathrm{~mm} . \mathrm{Hg}$, base deficit $1 \mathrm{mEq} / 1$. The baby was given intramuscular erythromycin and streptomycin and intravenous $10 \%$ dextrose; he continued to be nursed in high oxygen atmosphere $(45 \%)$, which was gradually reduced. The following day he was breathing regularly with no insuction and capillary $\mathrm{pH}$ $7 \cdot 37, \mathrm{PCO}_{2} 40 \mathrm{~mm} . \mathrm{Hg}$, base deficit $7 \mathrm{mEq} / \mathrm{l}$. However, the infant remained hypotonic and staring with depressed reflexes. Thrombotest was 5\% of normal. A small pneumothorax persisted with clinical and radiological signs of interstitial emphysema for five days with scattered radio-translucent areas. The intrapleural tube was removed on the third day. Cerebral signs persisted for eight days with slow improvement. The infant was discharged apparently well after a normal chest radiograph.

\section{Discussion}

It is important to consider the possibility of interstitial emphysema, which may progress to mediastinitis or tension pneumothorax and death, in an infant presenting with cyanosis or respiratory distress in the immediate newborn period. Usually it is associated with trauma or resuscitation, especially positive pressure, but occasionally it occurs unrelated to this (as in our four cases) and is probably due to air trapping in the alveoli which become blocked by hyaline membrane, amniotic fluid or other debris. Overdistension and rupture of the base of the air sacs occur and lead to the escape of air into the interstitial tissues. The presence of air in the interstitial tissues may produce splinting of the lungs, especially at inspiration, and a subsequent increase in residual air and reduction in tidal volume and respiratory reserve (Macklin and Macklin, 1944). Clinically, it may pass unnoticed initially, or there may be features of respiratory distress, intermittent or permanent cyanosis, fine crepitations, distant heart sounds, overdistension and fixation of the chest wall, and occasionally surgical emphysema. It may follow respiratory distress syndrome as occurred in Case 2. The radiograph may be diagnostic and show a coarse reticular granular patterning which should be distinguished from the finer reticular granular patterning seen in the respiratory distress syndrome, the emphasis being on the translucencies rather than the opacities (Fig. 3). The air bronchogram is a prominent feature in the respiratory distress syndrome, but is absent from the radiograph of interstitial emphysema. In addition the border of the heart in interstitial emphysema is 
radiologically more clearly defined than it is in the respiratory distress syndrome.

Recognition of the condition is made easier by the occasional appearance of larger radio-translucent areas representing bubbles of air varying in diameter from 0.5 to $3 \mathrm{~mm}$. scattered in the substance of the lung, and sometimes of an associated pneumothorax (Fig. 3). Care should be taken not to mistake the skin lines for a pneumothorax. Interstitial pulmonary emphysema with progression to pneumomediastinum and tension pneumothorax is a potentially treatable condition, and its early recognition is important (Case 4). When the diagnosis is made the infant's disability should be assessed. If gross cyanosis or distress is not present or if there is no pneumothorax seen on radiography, then observation and preparation for insertion of cannula with underwater drainage is sufficient. But if the infant is severely affected (for example Case 2) he should be seen frequently, and serial radiographs taken to determine the onset of pneumothorax, and if there is any deterioration in condition an underwater drain should be inserted (Case 3).
Summary

Four cases of neonatal interstitial pulmonary emphysema with tension pneumothorax are described. A radiological picture thought to be a feature of this condition is also described. The need for early recognition, close observation and sometimes urgent treatment with underwater drainage is emphasized.

I wish to express my appreciation to Professor A. G. Watkins, Dr. O. P. Gray, Dr. K. M. Laurence and Dr. G. Hinde for their advice in the preparation of this paper, and to the Cardiff Royal Infirmary Medical Illustration Department for the photographs.

\section{REFERENCES}

Donald, I. (1954). Radiology in neonatal respiratory disorders. Brit. J. Radiol., 27, 500.

Macklin, M. T. and Macklin, C. C. (1944). Malignant interstitial emphysema of the lungs and mediastinum as an important occult complication in many respiratory diseases and other conditions : an interpretation of the clinical literature in the light of laboratory experiment. Medicine (Baltimore), 23, 281. 